MR. MUIDEEN OLAIYA (Orcid ID : 0000-0002-4070-0533)

DR. DOMINIQUE A CADILHAC (Orcid ID : 0000-0001-8162-682X)

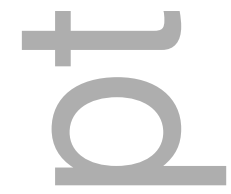

Article type : Original Papers

\title{
Effectiveness of a Shared Team Approach between Nurses and Doctors For Improved Risk Factor Management (STANDFIRM) in survivors of stroke: a cluster randomised controlled trial
}

Muideen T. Olaiya, M.Sc ${ }^{1 *}$; Joosup Kim, Ph.D ${ }^{1,2^{*}}$; Mark R. Nelson, Ph.D ${ }^{3,4}$; Velandai K. Srikanth, Ph.D ${ }^{1,3}$; Christopher F. Bladin, Ph.D ${ }^{5}$; Richard P. Gerraty, Ph.D ${ }^{6}$; Sharyn M. Fitzgerald, Ph.D ${ }^{4}$; Thanh Phan, Ph.D ${ }^{1}$; Judith Frayne, $\mathrm{MBBS}^{7}$; Dominique A. Cadilhac, Ph. ${ }^{1,2 \dagger}$; Amanda G. Thrift, Ph.D ${ }^{1 \dagger}$; on behalf of the STANDFIRM investigators. * equal first authors, ${ }^{\dagger}$ equal senior authors

${ }^{1}$ Stroke and Ageing Research, Monash University, Australia

${ }^{2}$ Stroke Division, the Florey Institute of Neuroscience and Mental Health, Australia

${ }^{3}$ Menzies Institute for Medical Research, Australia

${ }^{4}$ Department of Epidemiology and Preventive Medicine, Monash University, Australia

${ }^{5}$ Department of Neurosciences, Box Hill Hospital, Australia

${ }^{6}$ Department of Medicine, Epworth Healthcare, Australia

This is the author manuscript accepted for publication and has undergone full peer review but has not been through the copyediting, typesetting, pagination and proofreading process, which may lead to differences between this version and the Version of Record. Please cite this article as doi: $10.1111 /$ ENE.13306

This article is protected by copyright. All rights reserved 


\title{
Correspondence:
}

Amanda Thrift

Stroke and Ageing Research, Monash University, Australia

Phone: +61385722648. Fax:+61399024245. Email: amanda.thrift@monash.edu

Running title: Risk factor management for secondary prevention of stroke

Keywords: randomised clinical trial, risk factors, stroke, TIA, secondary prevention

Disclosures: Dr. Phan has received honoraria for presentations given for Bayer/Boehringer Ingelheim/Genzyme/Pfizer/BMS.

\begin{abstract}
Background: Limited evidence exists on benefits of organised care for improving risk factor control in patients with stroke or transient ischaemic attack (TIA). We determined the effectiveness of an individualised management program in reducing absolute cardiovascular disease risk in this high-risk population.
\end{abstract}

Methods: Prospective, multicentre, cluster-randomised controlled trial, with blinded assessment of outcomes, and intention-to-treat analysis. Patients hospitalised for stroke/TIA and aged $\geq 18$ years were recruited from four hospitals. General practices treating recruited patients were randomised to either provide usual care, or an individualised management program, comprising nurse-led education, and review of care plans by stroke specialists, in addition to usual care. Primary outcome: change in Framingham cardiovascular risk score between baseline and 12 months.

Results: From January 2010 and November 2013, 156 general practices (280 patients) were randomly assigned to usual care (control), and 159 (283 patients) to the intervention. The median age was 70.1 years; $65 \%$ were male. Overall, $>80 \%$ of participants were prescribed recommended secondary prevention therapies at baseline. The primary efficacy analysis comprised 533 participants, with 30 either dying or lost to follow-up. In adjusted analyses, 
we found no significant between-group difference in the cardiovascular risk score at 12 months $(0.04,95 \%$ CI $-1.7,1.8)$.

Conclusions: The effectiveness of an organised secondary prevention program for stroke may be limited in patients from high-performing hospitals with regular post-discharge follow-up and communication with general practices.

\section{Introduction}

Survivors of stroke often experience severe secondary outcomes associated with the presence of risk factors [1]. Effective management of risk factors could reduce the risk of these outcomes by up to $80 \%$ over a 10 -year period [2]. However, control of risk factors in survivors of stroke is often poor [3], potentially reflecting inadequate implementation of secondary prevention therapies. In a population-based stroke incidence study conducted in Melbourne, Australia, only 34\% of participants were on optimal treatment between 2007 and 2009 [4]. Clearly, opportunities exist to optimise the management of risk factors in this highrisk population, this providing a strong rationale for this study.

Evidence-based strategies to improve the risk factor profile in survivors of stroke or transient ischaemic attack (TIA) post-discharge comprise both pharmacological and lifestyle interventions [5]. These strategies could be enhanced by adopting a multidisciplinary approach. However, benefits of multidisciplinary interventions in reducing vascular risk after a stroke/TIA are uncertain [6,7].

General practices are well placed to implement and coordinate prevention strategies. As a result, the Australian government created a policy framework to encourage general practitioners (GPs) to coordinate comprehensive, multidisciplinary, and individualised management of complex chronic diseases, such as stroke [8]. Despite the existence of this framework, there is no evidence for its effectiveness in stroke. We investigated the effectiveness of an evidence-based individualised management program, already existing in a funded framework, for improving the risk factor profile in survivors of stroke/TIA.

\section{Methods}


The full study protocol, including sample size calculation and statistical analysis plan, has been published elsewhere $[9,10]$. The methods are summarised below.

\section{Trial design and participants}

The Shared Team Approach between Nurses and Doctors For Improved Risk Factor Management (STANDFIRM) is a pragmatic multicentre, cluster-randomised, controlled trial, with blinded assessment of outcomes, and intention-to-treat analysis. Patients hospitalised with stroke or TIA were recruited from four major tertiary hospitals in Melbourne, Australia. Patients were eligible if aged $\geq 18$ years and living within $50 \mathrm{~km}$ of the closest recruitment hospital. Exclusion criteria were enrolment in another clinical trial, admission from/discharge to a nursing home, or presence of rapidly deteriorating disease. Potential participants were approached in hospital to request consent for participation. To reduce the risk of drop-out, final consent was obtained at an in-home patient visit. Appropriate ethics approval was obtained (HREC number 2011000331). STANDFIRM is registered with the Australian New Zealand Clinical Trials Registry (ACTRN12608000166370).

\section{Randomisation and blinding}

Participants were randomised to receive the intervention or usual care, using a computergenerated block design. This was to ensure that study groups had equal distribution of patients from participating hospitals, and to eliminate bias from potential variation in postacute treatment. To reduce contamination between groups, randomisation was clustered by general practice. Participants, assessors, specialists, and GPs were blinded to the intervention and group allocations.

\section{Usual care}

Patients in the usual care group received the usual care arrangement in the stroke prevention clinic of participating hospitals and usual general practice management.

\section{Intervention}

In addition to usual care, participants in the intervention group received an individualised management program comprising a chronic disease management (CDM) plan, constructed to meet requirements for remuneration under Medicare [8], and stroke-specific education. Using health information recorded by blinded assessors at baseline assessments (described below), 
an initial CDM plan was developed for participants by an unblinded intervention nurse in consultation with independent stroke specialists. The plan, containing clear health goals for risk factors, was provided to GPs to facilitate the care of their patients (Supporting Information Data S1). Australian GPs are familiar with the format of the CDM plan, as they routinely use a similar format for treating other chronic conditions such as hypertension and diabetes.

The intervention nurse also made a home visit to provide education tailored towards the risk factor profile of participants. During this visit, participant's healthcare needs and problems, potential health goals, and strategies to overcome barriers were discussed. The nurse also organised appointment for participants to discuss the CDM plan with their GP. GPs were remunerated for using the CDM plan, providing an incentive for them to participate in the trial, as well as a pathway for implementation of trial outcomes.

The process of blinded assessment (described below), preparation of CDM plan, education visit, and arrangement of GP appointment, was repeated at 3 months after baseline. At this 3month visit, the nurse discussed barriers and enablers to health goals identified in the earlier visit. At 6 months, the CDM plan was revised again, based on updated information provided during a telephone interview.

\section{Baseline and outcome assessments}

Demographic information and details of stroke were obtained from medical records during hospitalisation. Baseline assessments were conducted at home by blinded assessors (median 10 weeks post-discharge). These included standardised assessment of blood pressure (BP) and anthropometry, biochemical tests, and self-reported lifestyle habits. These assessments were repeated at 3 and 12 months, while a brief telephone interview was conducted at 6 months after baseline.

\section{Primary outcome}

The primary outcome was a change in the updated general cardiovascular Framingham Risk Score (FRS) between baseline and 12 months [11]. The FRS is a validated tool for predicting cardiovascular events. The estimation of FRS includes sex, age, cholesterol levels, systolic $\mathrm{BP}$, use of antihypertensives, smoking status, and uncontrolled diabetes [10]. In Australia, the 
FRS model is a good predictor of absolute cardiovascular risk, and is routinely used in primary care settings [12].

\section{Secondary outcomes}

Secondary outcomes comprised changes between baseline and 12 months in the modified general cardiovascular FRS; systolic/diastolic BP; adverse events; use of antihypertensive, cholesterol-lowering, and antithrombotic therapies; and engagement in risk-modifying habits such as smoking cessation, recommended intake of alcohol, vegetables, fruit, and salt, and increased physical activity [9,10]. The modified FRS was estimated using the score sheet method [11], and other factors currently incorporated in guidelines [5].

\section{Statistical analysis}

As specified preyiously [10], all analyses were based on intention-to-treat. To ensure statistical efficiency and minimise bias, missing data were replaced with measurements obtained at other outcome assessments. For example, missing baseline or 12-month data were replaced with 3-month data. There were no participants with both baseline and 12-month data missing.

Descriptive statistics were used. Participant characteristics were compared using MannWhitney U test (continuous variables) and chi-square test (categorical variables). Withingroup differences were estimated using the paired-sample Wilcoxon signed-rank test (continuous variables) and McNemar's test (categorical variables). Confidence intervals for the Wilcoxon signed-rank test were determined using Somers' D test [13].

Effectiveness of the intervention on change in FRS at 12 months relative to baseline was determined using multivariable analysis of covariance and generalised linear regression models, adjusting for baseline FRS. Models were adjusted for any potential confounding factor (i.e. factors that demonstrated possible association with a change in FRS in the univariable model based on a P-value of $\leq 0.15$ ), or any baseline factor with possible heterogeneity between groups (based on a P-value of $\leq 0.15$ ). Potential cluster effect was investigated using a multilevel mixed-effects generalised linear model. The intra-cluster correlation coefficient approached zero $\left(1.4 \times 10^{-11}\right)$, indicating no variability in FRS measurements between recruitment sites. 
Similarly, multivariable generalised linear models were used to determine the effectiveness of the intervention on secondary outcomes, using link functions of linear (continuous outcomes), Poisson (count outcomes), or logistic (binary outcomes) regression. All analyses were conducted using STATA IC 12.1 (StataCorp, USA, 2012). Two-sided P-values of $<0.05$ were considered statistically significant.

\section{Results}

\section{Participant flow and baseline characteristics}

Overall, 5633 patients were assessed for eligibility between January 2010 and November 2013, 2516 (45\%) were eligible for recruitment, and 563 (22\% of eligible patients) were randomised: 283 to the intervention, and 280 to usual care (Fig. 1). There was no difference in baseline characteristics between study groups (Table 1). The median (Q1, Q3) age was $70.1(60.9,78.6)$ years, $65 \%$ were male, $78 \%$ had an ischaemic stroke, and $78 \%$ had no significant disability (defined as modified Rankin Scale score of 0-1). The median (Q1, Q3) time to randomisation was $73(54,97)$ days post-discharge. At baseline, $>80 \%$ of participants were prescribed recommended medications: antihypertensive (84\%), cholesterol-lowering (86\%), and antithrombotic (91\%) therapies. For the primary efficacy analysis, 533 participants (95\%) were included, 267 in the intervention group and 266 controls (Fig. 1). Overall, $72 \%$ of participants in the intervention group received all three intervention contacts (two home education visits and one telephone call), while $24 \%$ received two contacts (Supporting Information Table S1).

\section{Primary outcome analyses}

After adjusting for baseline FRS, we found no significant difference in the median FRS between groups at 12 months $(0.04,95 \%$ CI -1.7, 1.8; Table 2). Similarly, there were no significant between-group differences in covariates that contribute to the FRS at 12 months relative to baseline. Results were similar after adjusting for clustering.

\section{Secondary outcome analyses}

After adjusting for baseline estimates and potential confounding factors, there were no detectable between-group differences in the modified FRS (score sheet method), and BP at 12 months (Table 3). Similarly, there were no between-group differences in adverse events, adherence to medications, and lifestyle habits at 12 months (Table 3). 


\section{Discussion}

To the best of our knowledge, our study is the first to investigate the effectiveness of a structured and multidisciplinary program for secondary prevention of stroke that was already embedded in existing funding policy. In survivors of stroke/TIA, there was no detectable effect of our intervention in reducing the absolute cardiovascular risk as estimated by the FRS over a 12-month period. Similarly, there was no detectable improvement in any of the measured individual clinical indicators of stroke risk.

The lack of impact of our intervention over usual practice likely reflects the high level of performance in the usual processes of care for stroke prevention in participating recruitment hospitals. Indeed, our participants appeared to be well treated, as $\geq 80 \%$ were discharged on medications according to guidelines. These data reflect performance that is better than national estimates $[14,15]$, and estimates obtained in the study region at the time the study was conceived [4]. For instance, $84 \%$ of our participants were discharged on antihypertensive medications at baseline, compared to $59 \%$ in a previous (1997-1999) population-based study [4], and 71\% reported recently (2013) by the Australian Stroke Clinical Registry [14]. Similar trends were observed for patients with ischaemic stroke and atrial fibrillation discharged on anticoagulant therapy [15]. Importantly, the actual proportion of eligible participants prescribed these agents may be underestimated in the present study as some participants were not prescribed medications for valid clinical reasons.

Similarly, our estimates for prescription of secondary prevention therapies are better than those reported in other studies. In a trial conducted in Denmark to investigate the effectiveness of a nurse-led intervention to control BP in patients with stroke/TIA, $63 \%$ of participants were on antihypertensive medications ( $81 \%$ in our study), while $61 \%$ were on cholesterol-lowering medications (90\% in our study), at baseline [16].

The management of patients in our study may reflect ongoing care or residual effects of specialist acute care provided by participating hospitals. For example, there were procedures for routine review of patients after discharge from Monash Medical Centre, where 54\% of our participants were recruited [personal communication, Thanh Phan], and other participating hospitals [personal communication, Christopher Bladin]. Therefore, it appears that an additional intervention may not be required to supplement usual post-discharge practice adopted in these high-performing hospitals. 
Studies on post-discharge care interventions have not shown significant reductions in levels of risk factors for stroke [7]. In a study similar to ours, an individualised multidisciplinary intervention, involving periodic home visits and telephone follow-ups, did not improve the control of any of the risk factors investigated after 6 months of follow-up [17]. In contrast to most of the interventions investigated previously [7], a nurse-led intervention, involving lifestyle counselling and physician-assisted review of medications, improved control of BP and low-density lipoprotein cholesterol in Swedish survivors of stroke/TIA after 12 months of follow-up [18]. Participants in this Swedish study appeared to be well treated at baseline, although treatment was not as great as observed in our study.

Another possible explanation for the ineffectiveness of our intervention may be the contamination of the control group through post-discharge care provided by participating hospitals or general practices. During the course of our study (2010-2014), Medicare benefits for use of CDM plan rose by $70 \%$ in the study region [19]. Given these changes in practice, it is possible that a significant proportion of the controls may have been provided a care plan.

The main strength of our study is its robust design, the large sample size, and careful and extensive assessment of clinically relevant outcomes, including those that were not reported previously. Another major strength of this study is the adjustment of baseline data to eliminate potential biases resulting from repeated measures.

A major limitation of this study is that the primary outcome, FRS, was originally developed to assess risk in individuals with no clinical manifestation of vascular disease [11]. However, an advantage of the FRS is that most of its components are modifiable risk factors for incident/recurrent stroke and therefore highly relevant for our study. We expect any potential underestimation of risk by the FRS to be homogenous across study groups and therefore unlikely to affect the net difference in outcome between groups. Another limitation of this study is that our findings may not be generalised to the wider stroke population as a result of potential selection bias from low overall recruitment rate. The generalisability of our findings is also limited by the fact that our sample appeared to be better treated and had less severe stroke, as reflected by large proportions of participants who were on recommended treatment or who had no significant disability. There is also possibility of contamination of the control group as highlighted earlier. We are presently seeking approval for data linkage with the Australian Medicare Benefits Schedule to ascertain the presence/extent of these potential sources of contamination. 
In conclusion, our study did not provide evidence for the effectiveness of a comprehensive, coordinated and patient-centred care for managing risk factors in patients with stroke/TIA. However, this finding should be interpreted with caution as our trial was performed in participants recruited from high-performing hospitals where usual care was close to optimal. This model of care is more likely to be beneficial in settings where there is poor compliance to the management of stroke, and where there is lack of adequate specialist follow-up, or lack of communication with GPs on the care of survivors.

Acknowledgements: We appreciate the hard work and dedication of the research nurses.

Funding: National Health and Medical Research Council (586605, 1042600, 1063761, 1061457).

\section{References}

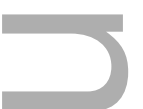

1. Putaala J, Haapaniemi E, Kaste M Tatlisumak T. How does number of risk factors affect prognosis in young patients with ischemic stroke? Stroke. 2012; 43: 356-361.

2. Hackam DG, Spence JD. Combining multiple approaches for the secondary prevention of vascular events after stroke: a quantitative modeling study. Stroke. 2007; 38: $1881-1885$.

3. Shah NS, Huffman MD, Ning H, Lloyd-Jones DM. Trends in vascular risk factor treatment and control in US stroke survivors: the National Health and Nutrition Examination Surveys (1999-2010). Circ Cardiovasc Qual Outcomes. 2013; 6: 270277

4. Thrift AG, Kim J, Douzmanian V, et al. Discharge is a critical time to influence 10year use of secondary prevention therapies for stroke. Stroke. 2014; 45: 539-544.

5. National Stroke Foundation - Australia. Clinical guidelines for stroke management 2010.

https://www.nhmrc.gov.au/_files_nhmrc/publications/attachments/cp126.pdf (accessed 08/05/2015).

6. Fens M, Vluggen T, van Haastregt JC, Verbunt JA, Beusmans GH, van Heugten CM. Multidisciplinary care for stroke patients living in the community: a systematic review. J Rehab Med. 2013; 45: 321-330. 
7. Lager KE, Mistri AK, Khunti K, Haunton VJ, Sett AK, Wilson AD. Interventions for improving modifiable risk factor control in the secondary prevention of stroke. Cochrane Database Syst Rev. 2014; 5: CD009103.

8. Australian Government Department of Health. Chronic disease management: provider information.

http://www.health.gov.au/internet/main/publishing.nsf/Content/mbsprimarycarefactsheet-chronicdisease.htm (accessed 02/06/2015).

9. Thrift AG, Srikanth VK, Nelson MR, et al. Risk factor management in survivors of stroke: a double-blind, cluster-randomized, controlled trial. Int J Stroke. 2014; 9: 652657.

10. Thrift AG, Olaiya MT, Phan TG, et al. Statistical analysis plan (SAP) for Shared Team Approach between Nurses and Doctors For Improved Risk Factor Management (STANDFIRM): a randomised controlled trial. Int J Stroke. 2015; 10: 770-772.

11. D'Agostino RB Sr, Vasan RS, Pencina MJ, et al. General cardiovascular risk profile for use in primary care: the Framingham Heart Study. Circulation. 2008; 117: 743-753.

12. National Vascular Disease Prevention Alliance. Guidelines for the management of cardiovascular disease risk.

https://strokefoundation.com.au/what-we-do/treatment-programs/clinicalguidelines/guidelines-for-the-assessment-and-management-of-absolute-cvd-risk (accessed 09/09/2016).

13. Newson R. Confidence intervals for rank statistics: Percentile slopes, differences, and ratios. Stata J. 2006; 6: 497-520.

14. Cadilhac DA, Lannin NA, Anderson CS, et al. The Australian Stroke Clinical Registry annual report 2013.

http://www.auscr.com.au/wp-content/uploads/AuSCR-AnnualReport-2013-

FINAL.pdf (accessed 02/06/2015).

15. Andrew N, Kilkenny M, Harris D, Price C, Cadilhac DA. Outcomes for people with atrial fibrillation in an Australian national audit of stroke care. Int J Stroke. 2014; 9: $270-277$.

16. Hornnes N, Larsen K, Boysen G. Blood pressure 1 year after stroke: the need to optimize secondary prevention. J Stroke Cerebrovasc Dis. 2011; 20: 16-23.

17. Allen K, Hazelett S, Jarjoura D, et al. A randomized trial testing the superiority of a postdischarge care management model for stroke survivors. J Stroke Cerebrovasc. 2009; 18: 443-452. 
18. Irewall AL, Ogren J, Bergstrom L, Laurell K, Soderstrom L, Mooe T. Nurse-led, telephone-based, secondary preventive follow-up after stroke or transient ischemic attack improves blood pressure and LDL cholesterol: results from the first 12 months of the randomized, controlled NAILED stroke risk factor trial. Plos One. 2015; 10.

19. Australian Government Department of Human Services. Medical Benefits, Schedule Item Reports.

http://medicarestatistics.humanservices.gov.au/statistics/mbs_item.jsp. （accessed 27/07/2015).

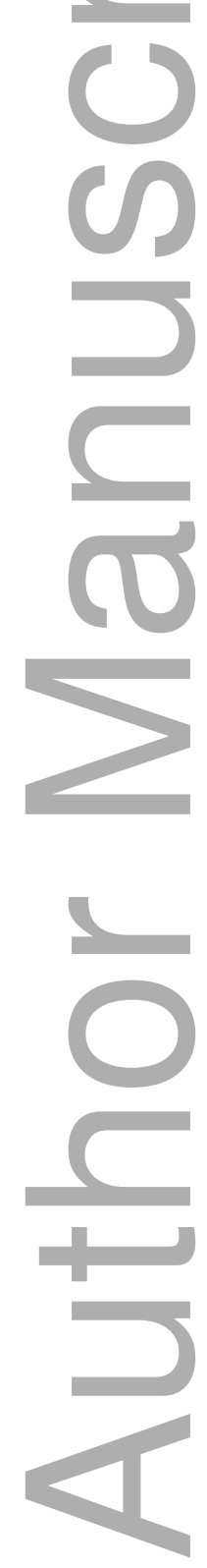


Fig. 1. Selection of participants, and reasons for inclusion and exclusion of participants ${ }^{a}$ Patients may have more than one reason; ${ }^{b}$ Includes concurrent illness, dementia, or palliated; 'Include too late to recruit, uncontactable, event not stroke, or moving interstate; ${ }^{\mathrm{d}}$ Intervention comprises an individualised management plan in addition to usual care.

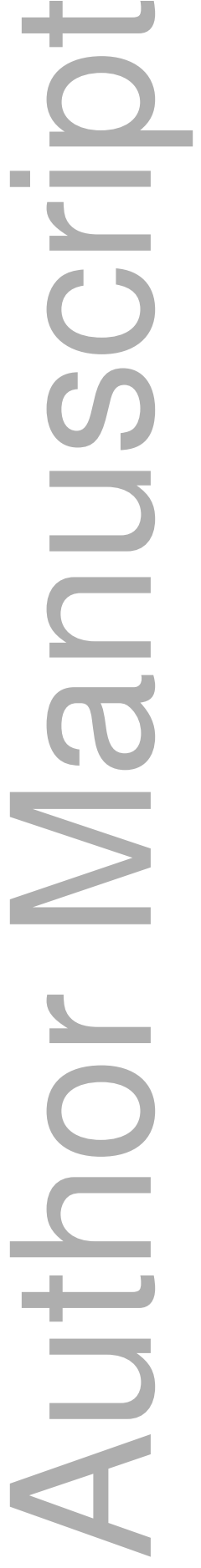




\section{STANDFIRM Investigators:}

\section{Steering Committee}

Amanda G. Thrift, Dominique A. Cadilhac, Velandai K. Srikanth, Mark R. Nelson, Christopher F. Bladin, Richard P. Gerraty, Sharyn M. Fitzgerald, Thanh Phan, Judith Frayne

\section{Data and Safety Monitoring Committee}

Colin I. Johnston, Julie Bernhardt, Richard A.L. Macdonell, Leonid Churilov

\section{Affiliations}

Stroke and Ageing Research, Monash University (AGT, DAC, VKS, TP), Menzies Institute for Medical Research (MRN), Department of Neurosciences, Box Hill Hospital (CFB), Department of Medicine, Epworth Healthcare (RPG), Department of Epidemiology and Preventive Medicine, Monash University (SMF), Department of Neurology, Alfred Hospital (JF), Baker IDI Heart and Diabetes Institute (CJ), The Florey Institute of Neuroscience and Mental Health (JB, LC), Department of Neurology, Austin Health (RALM)

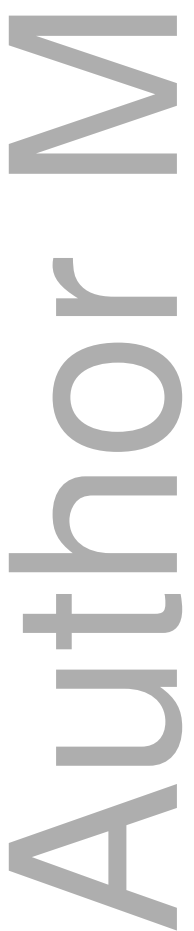


Intervention group N (\%) Usual Care group N (\%)

\begin{tabular}{|c|c|c|}
\hline & $(n=283)$ & $(n=280)$ \\
\hline \multicolumn{3}{|l|}{ Age (years) } \\
\hline Median (Q1, Q3)) & $69.0(60.8,78.4)$ & $71.2(60.9,79.1)$ \\
\hline$\leq 60$ & $72(25.4)$ & $71(25.4)$ \\
\hline $61-70$ & $79(27.9)$ & $68(24.3)$ \\
\hline $71-80$ & $86(30.4)$ & $86(30.7)$ \\
\hline$>80$ & $46(16.3)$ & $55(19.6)$ \\
\hline Female & $96(33.9)$ & $104(37.1)$ \\
\hline \multicolumn{3}{|l|}{ Body mass index $\left(\mathrm{kg} / \mathrm{m}^{2}\right)$} \\
\hline Median (Q1, Q3) & $27.5(24.3,30.9)$ & $28.0(25.1,31.4)$ \\
\hline$<25.00$ & $85(30.0)$ & $68(24.3)$ \\
\hline $25.00-29$ & $110(38.9)$ & $112(40.0)$ \\
\hline$\geq 30.00$ & $88(31.1)$ & $100(35.7)$ \\
\hline \multicolumn{3}{|l|}{ Biochemical measurements ${ }^{\text {a }}$} \\
\hline Systolic blood pressure (mmHg) & $135.5(123.0,148.0)$ & $133.5(119.0,146.0)$ \\
\hline Diastolic blood pressure $(\mathrm{mmHg})$ & $73.5(65.5,81.5)$ & $72.0(63.0,81.0)$ \\
\hline Glucose (mmol/L) & $5.2(4.7,5.9)$ & $5.2(4.8,6.1)$ \\
\hline Triglyceride $(\mathrm{mmol} / \mathrm{L})$ & $1.2(1.0,1.6)$ & $1.2(0.9,1.6)$ \\
\hline Total cholesterol (mmol/L) & $3.8(3.3,4.3)$ & $3.7(3.2,4.4)$ \\
\hline LDL cholesterol (mmol/L) & $1.9(1.5,2.4)$ & $1.8(1.4,2.3)$ \\
\hline HDL cholesterol (mmol/L) & $1.2(1.0,1.4)$ & $1.2(1.0,1.5)$ \\
\hline Urinary protein (g/day) & $0.09(0.06,0.12)$ & $0.08(0.06,0.12)$ \\
\hline $\mathrm{eGFR}\left(\mathrm{mL} / \mathrm{min} / 1.73 \mathrm{~m}^{2}\right)$ & $81.7(68.5,92.7)$ & $78.4(62.7,91.0)$ \\
\hline \multicolumn{3}{|l|}{ Type of stroke } \\
\hline Ischemic stroke & $217(76.7)$ & $219(78.2)$ \\
\hline Intracerebral hemorrhage & $28(9.9)$ & $19(6.8)$ \\
\hline Transient Ischemic Attack & $38(13.4)$ & $42(15.0)$ \\
\hline \multicolumn{3}{|l|}{ Disability (modified Rankin Scale) } \\
\hline 0 (No disability) & $83(29.3)$ & $81(28.9)$ \\
\hline 1 (No significant disability despite symptoms) & $136(48.1)$ & $138(49.3)$ \\
\hline 2-5 (Slight to severe disability) & $64(22.6)$ & $61(21.8)$ \\
\hline \multicolumn{3}{|l|}{ Medical history } \\
\hline Diabetes & $51(18.0)$ & $69(24.6)$ \\
\hline Hypertension & $178(62.9)$ & $198(70.7)$ \\
\hline Atrial fibrillation & $76(26.9)$ & $60(21.4)$ \\
\hline High cholesterol & $130(45.9)$ & $145(51.8)$ \\
\hline Proteinuria & $44(15.6)$ & $39(13.9)$ \\
\hline Stroke & $42(14.8)$ & $42(15.0)$ \\
\hline Other cardiovascular disease & $90(31.8)$ & $82(29.3)$ \\
\hline \multicolumn{3}{|l|}{ Behavioral factors } \\
\hline \multicolumn{3}{|l|}{ Smoking ${ }^{b}$} \\
\hline Never smoker & $106(37.5)$ & $123(43.9)$ \\
\hline
\end{tabular}




$\begin{array}{lcc}\text { Current smoker } & 23(8.1) & 19(6.8) \\ \text { Quit since stroke } & 25(8.8) & 23(8.2) \\ \text { Past smoker } & 129(45.6) & 115(41.1) \\ \text { Current risky drinking }^{c} & 12(4.2) & 15(5.4)\end{array}$

Drug use

$\begin{array}{lll}\text { Antihypertensive therapy } & 231(81.6) & 240(85.7)\end{array}$

$\begin{array}{lll}\text { Antiplatelet therapy } & 194(68.6) & 211(75.4)\end{array}$

Anticoagulant therapy $\quad 78(27.6) \quad 54$ (19.3)

$\begin{array}{lll}\text { Cholesterol lowering therapy } & 245(86.6) & 240(85.7)\end{array}$

Note: Only 0-2\% missing values in all variables.

${ }^{a}$ Data are expressed in median $(\mathrm{Q} 1, \mathrm{Q3})$; $^{\mathrm{b}}$ Current smoker is defined as smoking at the time of assessment. Past-smoker is defined as quitting before stroke; ${ }^{\mathrm{c}}$ Risky drinking is defined as $\geq 2$ drinks/day for women and $\geq 4$ drinks/day for men.

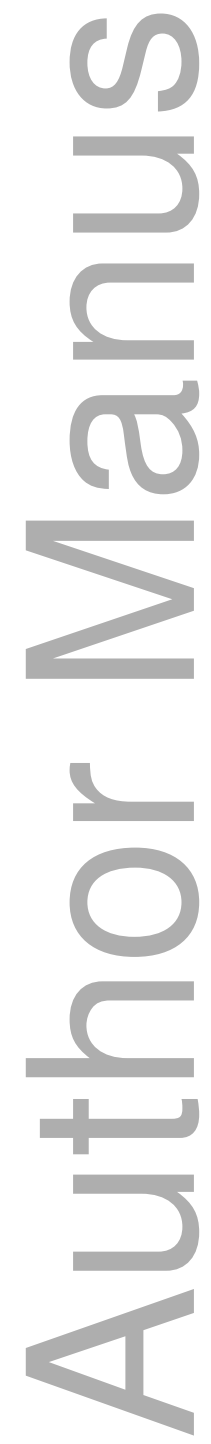


Table 2. Within- and between-group changes in primary outcome, its covariates, and adverse events, for intervention and control groups

\begin{tabular}{|c|c|c|c|c|c|c|c|}
\hline \multirow{2}{*}{ كי } & \multicolumn{3}{|c|}{ Intervention } & \multicolumn{3}{|c|}{ Control } & \multirow[b]{2}{*}{$\begin{array}{c}\text { Between-group } \\
\text { difference }(95 \% \mathrm{CI})\end{array}$} \\
\hline & Baseline $(n=283)$ & Follow-up $(\mathrm{n}=267)$ & $\begin{array}{c}\text { Difference }^{\text {a }} \\
(95 \% \mathrm{CI})\end{array}$ & Baseline $(\mathrm{n}=280)$ & Follow-up $(\mathrm{n}=266)$ & $\begin{array}{c}\text { Difference }^{\text {a }} \\
(95 \% \mathrm{CI})\end{array}$ & \\
\hline $\mathrm{FRS}^{\mathrm{b}}$ & $20.1(11.4,33.7)$ & $21.8(12.0,33.0)$ & $-0.007(-0.1,0.1)$ & $19.5(10.3,30.1)$ & $21.0(11.5,32.1)$ & $0.08(-0.06,0.2)$ & $-0.1(-1.8,1.6)$ \\
\hline \multicolumn{8}{|l|}{ Components } \\
\hline Age (years) & $69.0(60.8,78.4)$ & $69.8(61.8,79.7)$ & - & $71.2(60.9,79.1)$ & $71.1(60.7,80.0)$ & - & - \\
\hline Systolic BP (mmHg) & $135.5(123.0,148.0)$ & $135.0(122.5,150.0)$ & $0.05(-0.9,0.2)$ & $133.5(119.0,146.0)$ & $134.3(121.5,145.5)$ & $0.06(-0.9,0.2)$ & $0.05(-3.0,3.1)$ \\
\hline $\mathrm{HbA1c}(\%)$ & $5.8(5.6,6.1)$ & $5.8(5.6,6.1)$ & $-0.2(-0.3,-0.03)$ & $5.9(5.6,6.3)$ & $5.9(5.6,6.2)$ & $-0.04(-0.1,0.06)$ & $0.08(-0.3,0.5)$ \\
\hline Total cholesterol $(\mathrm{mmol} / \mathrm{L})$ & $3.8(3.3,4.3)$ & $3.8(3.4,4.4)$ & $0.2(0.03,0.3)$ & $3.7(3.2,4.4)$ & $3.8(3.2,4.6)$ & $0.1(-0.05,0.2)$ & $-0.008(-0.1,0.1)$ \\
\hline HDL cholesterol $(\mathrm{mmol} / \mathrm{L})$ & $1.2(1.0,1.4)$ & $1.3(1.0,1.5)$ & $0.2(0.01,0.3)$ & $1.2(1.0,1.5)$ & $1.3(1.0,1.5)$ & $0.1(-0.007,0.3)$ & $0.02(-0.02,0.06)$ \\
\hline Current smoking (\%) & $44(15.6)$ & $50(18.7)$ & $3.0(-0.6,6.6)$ & $44(15.7)$ & $41(15.4)$ & $0.0(-3.3,3.3)$ & - \\
\hline Antihypertensive therapy (\%) & $231(81.6)$ & $217(81.3)$ & $-0.4(-4.7,4.0)$ & $240(85.7)$ & $224(84.2)$ & $-1.1(-5.2,2.9)$ & - \\
\hline \multicolumn{8}{|l|}{ Potential covariates } \\
\hline $\mathrm{BMI}\left(\mathrm{kg} / \mathrm{m}^{2}\right)$ & $27.5(24.3,30.9)$ & $27.9(24.6,31.0)$ & $0.03(-0.1,0.2)$ & $28.0(25.1,31.4)$ & $27.8(25.2,31.1)$ & $-0.1(-0.3,0.001)$ & $0.1(-0.2,0.4)$ \\
\hline Triglyceride $(\mathrm{mmol} / \mathrm{L})$ & $1.2(1.0,1.6)$ & $1.2(0.9,1.6)$ & $0.02(-0.1,0.2)$ & $1.2(0.9,1.6)$ & $1.2(0.9,1.7)$ & $-0.01(-0.2,0.1)$ & $0.03(-0.07,0.1)$ \\
\hline Urinary protein (g/day) & $0.09(0.06,0.12)$ & $0.08(0.06,0.11)$ & $-0.07(-0.2,0.08)$ & $0.08(0.06,0.12)$ & $0.08(0.05,0.12)$ & $0.2(0.008,0.3)$ & $-0.5(-0.1,0.002)$ \\
\hline eGFR $\left(\mathrm{mL} / \mathrm{min} / 1.73 \mathrm{~m}^{2}\right)$ & $81.7(68.5,92.7)$ & $80.8(64.6,90.8)$ & $-0.2(-0.3,-0.04)$ & $78.4(62.7,91.0)$ & $78.7(64.8,90.3)$ & $-0.04(-0.2,0.1)$ & $0.6(-1.7,2.9)$ \\
\hline Current risky drinking $(\%$ & $12(4.2)$ & $15(5.6)$ & $1.1(-1.9,4.1)$ & $15(5.4)$ & $14(5.3)$ & $-0.4(-4.1,3.4)$ & - \\
\hline Antiplatelet therapy $(\%)$ & $194(68.6)$ & $176(65.9)$ & $-4.5(-9.4,0.4)$ & $211(75.4)$ & $185(69.6)$ & $-6.0(-10.8,-1.3)$ & - \\
\hline Anticoagulant therapy (\%) & $78(27.6)$ & $73(27.3)$ & $0.7(-2.2,3.7)$ & $54(19.3)$ & $61(22.9)$ & $3.3(0.0,6.8)$ & - \\
\hline Cholesterol lowering therapy (\%) & $245(86.7)$ & $226(84.6)$ & $-2.2(-7.1,2.6)$ & $240(85.7)$ & $219(82.3)$ & $-4.1(-8.4,0.2)$ & - \\
\hline \multicolumn{8}{|l|}{ Adverse events } \\
\hline Total (count) & & 173 & & & 161 & & \\
\hline Non-fatal vascular events ${ }^{d}$ & & 23 & & & 25 & & \\
\hline Fatal vascular events ${ }^{\mathrm{d}}$ & & 3 & & & 5 & & \\
\hline Adjusted FRS ${ }^{\text {e }}$ & & & & & & & $0.04(-1.7,1.8)$ \\
\hline
\end{tabular}

This article is protected by copyright. All rights reserved 


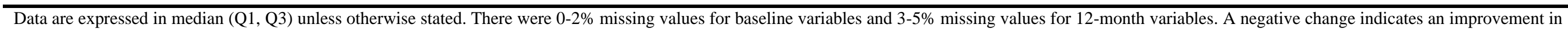
risk factor control except for HDL cholesterol, antihypertensive therapy, antiplatelet therapy, anticoagulant therapy, and cholesterol lowering therapy.

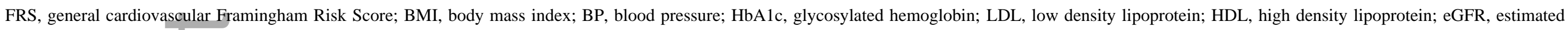
glomerular filtration rate

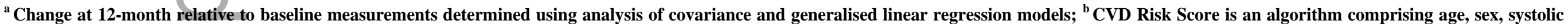

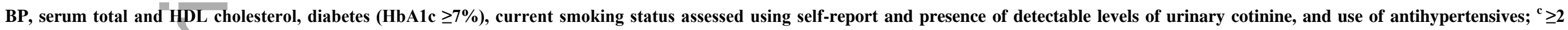

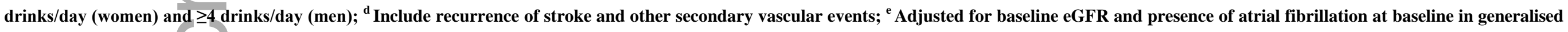
linear model.

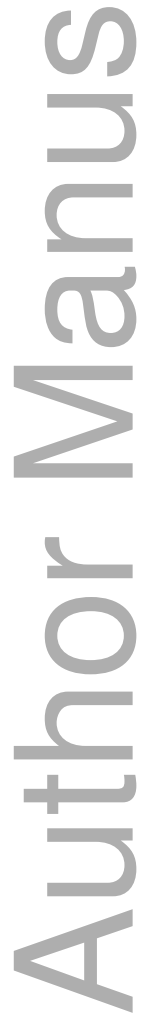

This article is protected by copyright. All rights reserved 
Table 3. Unadjusted and adjusted analyses of the effect of intervention on the secondary outcomes

\begin{tabular}{|c|c|c|c|c|}
\hline \multirow[b]{2}{*}{ Secondary outcomes } & \multicolumn{2}{|c|}{ Unadjusted } & \multicolumn{2}{|c|}{ Adjusted } \\
\hline & $\begin{array}{c}\text { Effect estimate }^{\text {a }} \\
(95 \% \text { CI })\end{array}$ & P-value & $\begin{array}{c}\text { Effect estimate }^{b} \\
(95 \% \mathrm{CI})\end{array}$ & P-value \\
\hline Modified FRS $^{c}$ & $0.9(0.6,1.4)$ & 0.638 & $0.9(0.6,1.5)$ & 0.708 \\
\hline Systolic BP (per mmHg) & $1.1(0.1,22.1)$ & 0.974 & $2.1(0.1,41.9)$ & 0.620 \\
\hline \multicolumn{5}{|l|}{ Adverse events (AEs) } \\
\hline Total AEs & $1.1(0.8,1.5)$ & 0.697 & $1.1(0.9,1.4)$ & 0.475 \\
\hline Non-fatal vascular events ${ }^{\mathrm{d}}$ & $0.9(0.5,1.6)$ & 0.745 & $0.9(0.5,1.5)$ & 0.584 \\
\hline Fatal vascular events ${ }^{\mathrm{d}}$ & $0.6(0.1,2.5)$ & 0.475 & $0.9(0.3,3.1)$ & 0.857 \\
\hline Antihypertensive therapy & $0.9(0.5,1.7)$ & 0.770 & $0.9(0.5,1.7)$ & 0.832 \\
\hline Cholesterol lowering therapy & $1.7(0.9,3.4)$ & 0.102 & $1.3(0.7,2.5)$ & 0.459 \\
\hline Antiplatelet therapy & $0.8(0.5,1.3)$ & 0.342 & $1.1(0.6,1.9)$ & 0.732 \\
\hline Anticoagulant therapy & $0.9(0.4,1.8)$ & 0.722 & $0.6(0.2,1.5)$ & 0.287 \\
\hline Current smoking ${ }^{\mathrm{e}}$ & $2.2(1.1,4.5)$ & 0.031 & $1.9(0.9,4.0)$ & 0.078 \\
\hline Current risky drinking $\|$ & $1.2(0.5,2.7)$ & 0.670 & $1.4(0.6,3.3)$ & 0.440 \\
\hline \multicolumn{5}{|l|}{ Healthy eating } \\
\hline$\geq 5$ servings of vegetables daily & $0.6(0.3,1.2)$ & 0.171 & $0.6(0.3,1.2)$ & 0.138 \\
\hline$\geq 2$ servings of fruit daily & $0.9(0.6,1.2)$ & 0.396 & $1.0(0.7,1.4)$ & 0.843 \\
\hline$<5 \mathrm{~g}$ salt daily & $0.5(0.2,1.3)$ & 0.169 & $0.6(0.2,1.4)$ & 0.216 \\
\hline Physically active ${ }^{\mathrm{f}}$ & $1.1(0.6,2.0)$ & 0.671 & $1.1(0.6,2.0)$ & 0.719 \\
\hline
\end{tabular}

FRS, general cardiovascular Framingham Risk Score; BP, blood pressure.

${ }^{a}$ Estimates of the univariable generalised linear regression model adjusting for baseline measurements, using link functions for linear (continuous outcomes), logistic (binary outcomes), and Poisson (count outcomes) regression; ${ }^{b}$ Estimates of the stepwise multivariable generalised linear regression model adjusting for baseline measurements and potential confounding factors. A separate model was fitted for each outcome; ${ }^{\mathrm{c}}$ Modified FRS is an algorithm comprising age, sex, systolic blood pressure, serum total and HDL cholesterol, diabetes, current smoking status, use of antihypertensive, antiplatelet therapy, anticoagulation, and lipid-lowering medications; ${ }^{d}$ Include recurrence of stroke and other secondary vascular events; ${ }^{\mathrm{e}}$ Self-report of current smoking status and presence of detectable levels of urinary cotinine; $\| \geq 2$ drinks/day (women) and $\geq 4$ drinks/day (men); ${ }^{f}$ Undertaking $\geq 30$ minutes of moderate-intensity activity or $\geq 20$ minutes of vigorous-intensity physical activity $\geq 3$ times/week. 


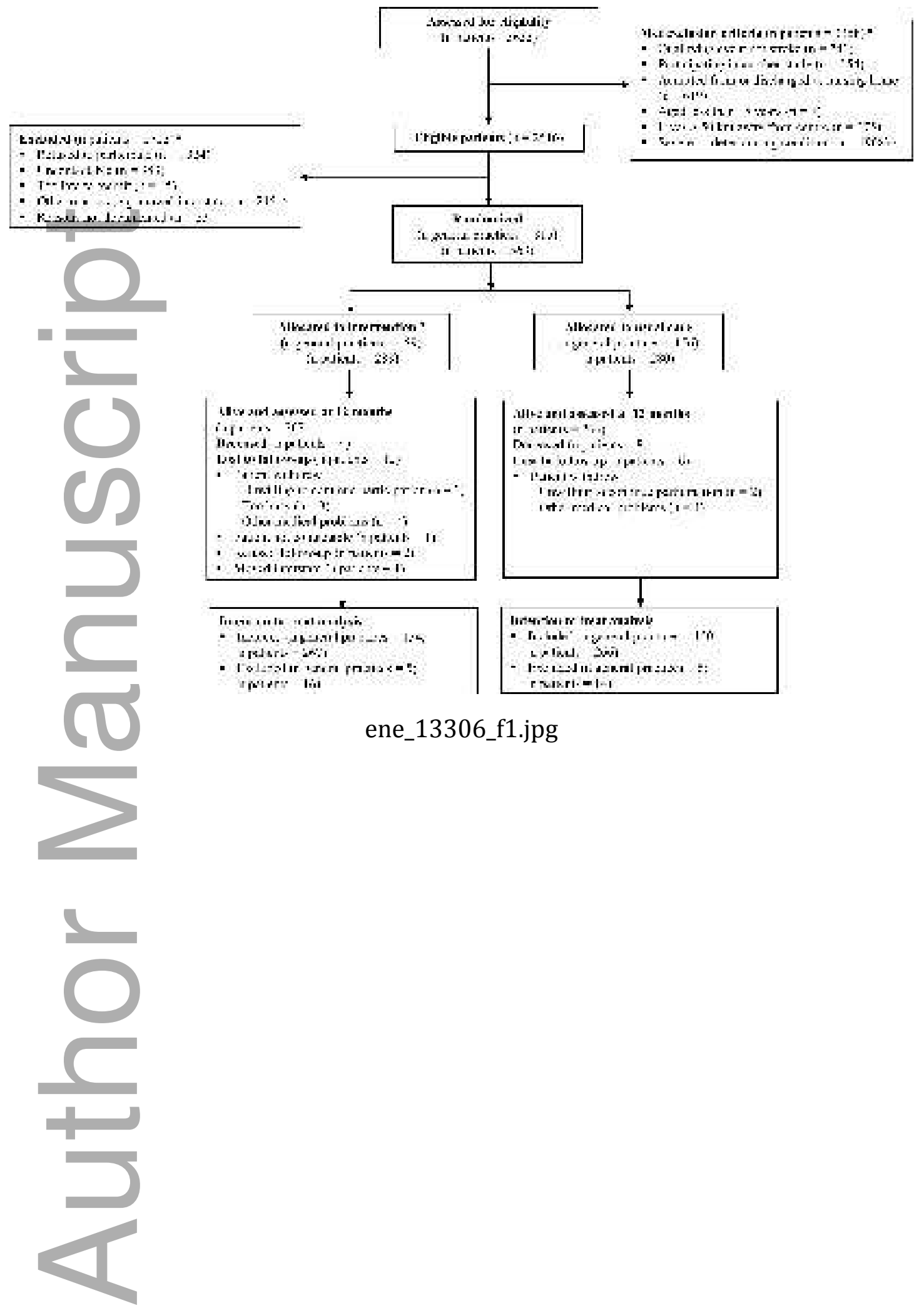

This article is protected by copyright. All rights reserved 


\section{University Library}

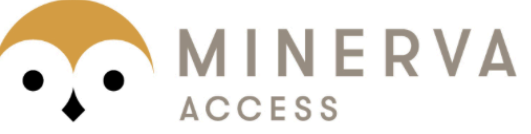

A gateway to Melbourne's research publications

Minerva Access is the Institutional Repository of The University of Melbourne

\section{Author/s:}

Olaiya, MT;Kim, J;Nelson, MR;Srikanth, VK;Bladin, CF;Gerraty, RP;Fitzgerald, SM;Phan, T;Frayne, J;Cadilhac, DA;Thrift, AG

Title:

Effectiveness of a shared team approach between nurses and doctors for improved risk factor management in survivors of stroke: a cluster randomized controlled trial

Date:

2017-07-01

\section{Citation:}

Olaiya, M. T., Kim, J., Nelson, M. R., Srikanth, V. K., Bladin, C. F., Gerraty, R. P., Fitzgerald, S. M., Phan, T., Frayne, J., Cadilhac, D. A. \& Thrift, A. G. (2017). Effectiveness of a shared team approach between nurses and doctors for improved risk factor management in survivors of stroke: a cluster randomized controlled trial. EUROPEAN JOURNAL OF NEUROLOGY, 24 (7), pp.920-928. https://doi.org/10.1111/ene.13306.

Persistent Link:

http://hdl.handle.net/11343/292888 